\title{
The Prospects and Challenges of PoS as Electronic Payment System in Nigeria
}

\author{
Amaefule, I.A. ${ }^{\# 1}$, Njoku, O. D. ${ }^{* 2}$, Agbakwuru, O. A. ${ }^{\# 3}$, Chilaka, U. L. ${ }^{\# 4}$ \\ ${ }^{\# 1,3,4}$ Department of Computer Science, Imo State University, Owerri, Nigeria \\ ${ }^{* 2}$ Department of Computer Science, Covenant Polytechnic, Owerrinta, Abia, Nigeria
}

\begin{abstract}
With the growing use of sophisticated electronic technology for e-financing globally, the introduction of PoS into the Nigeria economy has facilitated the ease of doing business without necessarily going about with huge cash in wallet. This paper has presented the prospects and challenges of Point of Sale (PoS) as electronic payment system in Nigeria. The study aimed to investigate the acceptance and issues surrounding the effective use of PoS for carrying out e-payment in Nigeria. Descriptive method was used to collect data from PoS merchants' customers, who were orally interviewed in Owerri. The responses obtained show that majority of the customers interviewed were of the opinion that PoS was convenient and fast. Also, majority expressed high level of trust on the use of PoS. However, significant number of the customers still maintained that network failure, excessive charge on the use of PoS for making payment, security, unlimited number of PoS and other financial transaction irregularities affect the efficient use of PoS. These challenges may hinder the full adoption or acceptability of PoS in Nigeria. These challenges are however not peculiar to growing economy like Nigeria and as such, with strong commitment by stakeholders including government and private businesses in the financial sector, the Nigeria economy will witness accelerated growth in the adoption of PoS for making epayment.
\end{abstract}

Keywords - Challenges, E-payment, Nigeria, PoS, Prospects

\section{INTRODUCTION}

The use of electronic payment (e-payment) system in carrying out financial services and transactions has taken a centre stage in the world economy with developing countries such as Nigeria harnessing it for growing their economic financial inclusiveness. These systems make use of Information and Communication Technology (ICT) network facilities. E-payment systems, as automated processes, are used to exchange monetary value among stakeholders doing business transactions and transferring this amount of money over ICT network (Ayo and Ukpere, 2010). E-payment can be done using Debit or credit cards, online portals, Point of Sales (PoS) terminals, Automated Teller Machines (ATMs), direct debit/deposit, and Real Time Gross Settlement (RTGS) system (Nnaka, 2009; Ayo and Ukpere, 2010).

This paper considers the PoS e-payment channels as a growing financial system that is gaining widespread acceptance in making payment in virtually all business locations in Nigeria today. According to online report by Kingston (2018), the use of PoS terminals for payments has made Nigerians to use less cash for financial transactions more than ever. For instance, a record of 1.4 trillion naira was achieved in Nigeria using PoS for making transaction in 2017 (Achebe, 2018; Kingston, 2018).

The use of PoS terminals to make financial payment in Nigeria was introduced by the Central Bank of Nigeria (CBN) in 2012 to promote its cashless policy with the aim of improving payment system. Ever since the introduction, there has been increasingly growth in the number of active PoS terminals provided by banks to mobile money merchants. In the first three months of 2018, for example, it was reported that a total of 17,193 PoS terminals were registered by banks for carrying out cashless transactions in Nigeria (Ogunfuwa, 2018). Statistical figures from the Nigeria Inter-Bank Settlement Scheeme (NIBSS) indicated that as of 2018, the number of active PoS terminals in Nigeria was 164,607. Also, in addition to this development, a record of 66.6\% rise in transactions using PoS across the country was registered as at January, 2018 compared to the value registered using PoS for transaction in January, 2017. This trends was maintained in February, 2018 where an increase of $60.61 \%$ was registered compared to February, 2017. The attribution to this growth can be acceptance of PoS terminals for making payment and increasing ICT network penetration in Nigeria. However, the gain recorded, this paper examines the prospects and challenges of PoS terminals in Nigeria. 


\section{LITERATURE REVIEW}

Nzaro and Magidi (2014) examines the role of e-payment systems in financial institutions. The research focused on savings bank in Zimbabwe. The authors found that the acceptance and use of e-payment systems had great impact on respondents concerns such as convenience, product and service variety, cost reduction, speedy payment, security and acceptability. However, the study revealed that respondents stated that issues such as high set up costs, internet fraud, and long query solving time as well as auditing challenges.

Achebe (2018) investigates the prospects and challenges of e-finance in Nigeria. The study indicated that a good number of the respondents have high level of trust in e-payment systems and accepted that it is fast and convenient.

Kabir et al (2015) carried out a literature review of e-payment system adoption from 2010-2015. It analyzed various methods that have been used by researchers. The authors stated that most of the works on e-payment adoption were done in developing countries especially in Africa, and the most engaged method was survey technique. The study revealed that past studies have most frequently use questionnaire for data collection with respondents usually bank customers and staff. It suggested that further studies should use different data collection instruments such as the structured interview and observation and a shift be made from banking sector.

Tijani and Ilugbemi (2015) examines the e-payment channels in the Nigeria banking sector and the impacts on national growth. The authors asserted that significant number of persons have access to the services provided through ATM, PoS, internet, mobile money and other channels of e-payment, and are safe, convenience and reliable. The authors maintained that due to the reliability of these electronic systems in supporting customers in carrying out transactions, e-payment channels have contributed to national development.

Adeoti (2013) examines the challenges to the efficient use of PoS terminals in Nigeria. The study indicated that the efficient use of PoS terminals in Nigeria is affected by issues such as unreliable network, power outage, limited number of PoS per merchant store, security of communication over transaction network.

Okeke et al (2017) examines the use of Extended Technology Acceptance Mode in predicting consumer adoption of PoS e-payment system in Nigeria. The study revealed that the perception of the usefulness and the perception of the ease of use have significant effect on the adoption (acceptance) of PoS terminals in Nigeria. Also, operational security reasonably impacts on perceive ease of use (PEOU) with less effect on perceive usefulness (PU). On the customer awareness (CA), PU and PEOU are significantly and positively impacted.

Khan et al (2017) carried out a comprehensive research on all areas of e-payment system. It considered the services provided by e-payment systems, associated security challenges and other factors that hinder the acceptance, and the way forward. The authors also analysed technical and organization issues that can arise in the cause of internal operation.

\section{RESEARCH METHOD}

The study was conducted in Owerri, the Imo State capital. Owerri is located at the heart of the South-eastern Nigeria. The city is on geographical location of Latitude 5.476310 and Longitude 7.025853. It has Global Positioning System (GPS) of $5^{\circ} 28^{\prime} 34.7160^{\prime \prime} \mathrm{N}$ and $7^{\circ} 133.0708^{\prime \prime}$ E. Elevation of $71 \mathrm{~m}$.

A descriptive method was used for data collection. Structured interview was used to obtain data. A total of 90 respondents were randomly sampled from the three local government areas that make up Owerri. To ensure data accuracy and validity, the respondents were customers who have come to make business transaction at PoS terminals/shops. That is, only ascertained customers of merchants were interviewed.

The data focused on the response from customers of PoS merchants based on the impact of PoS on their financial transactions using the channel. The respondents were asked to state how the use of PoS has impacted on their convenience, cost effectiveness, speed of payment, security, and accessibility. They were also asked to indicate their level of trust based on ranking and the challenges to efficient use of PoS.

\section{IV.ANALYSIS OF FINDINGS AND DISCUSSION}

\section{A. Gender and Age of Respondents}

The pie charts in Fig. 1 and Fig. 2, represent the gender and the age of respondents. It can be seen from the response on the genders that $54 \%$ of the respondents are male while $46 \%$ are females. Also, on the age of the 
respondents, majority of the respondents (33\%) between 21-25 years, this is followed by those between 26-30 (28\%) and those between 16-20 years (23\%), while the least set of respondents are those between 31 and above $(17 \%)$.

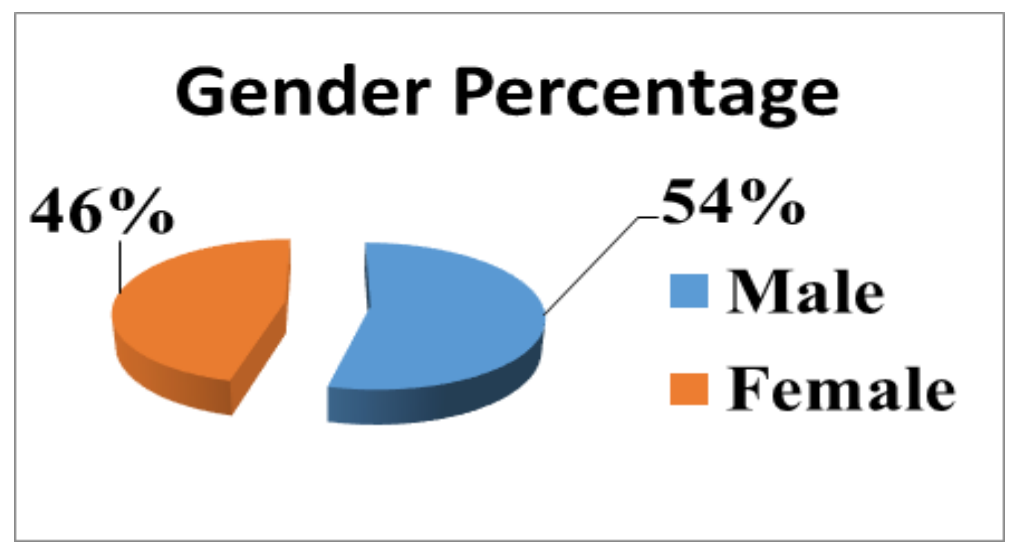

Fig. 1 Gender of respondents

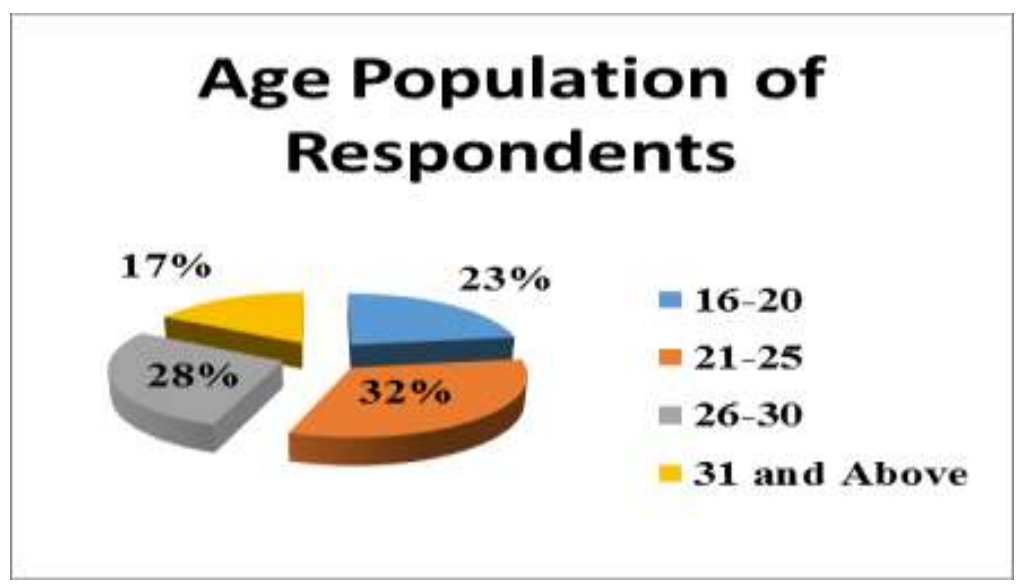

Fig. 2 Age of respondents

\section{B. Impact of PoS System}

In order to effectively analyse the impact of PoS system on the respondents (customers of PoS operators), the responses where based on Agree (A), Neutral (N), and Disagree (D). The response pattern is shown in Fig. 3. It can be seen that the six factors considered have positive impact on the respondents. Sixty five per cent $(65 \%)$ of the respondents agreed that use of PoS terminals for financial transaction is convenient, $12 \%$ were neutral in their response, and $23 \%$ disagreed, who alluded their feeling on the fact that sometimes they are debited with the transaction being unsuccessful. Resolving, the issues often times take days thereby making the convenience that should accompany such means of electronic transaction defeated. . All the respondents agreed that the use of PoS for making payment is fast $(100 \%)$. On the cost effectiveness, 55\% agreed, while 35\% of respondents disagreed. This they claimed that the cost charged by PoS operators is quite high with respect to the volume of transaction to be made. The charge, they maintained will not be incurred if they were to make transaction directly in their banks. On the security aspect, 55\% agreed, while 30\% disagreed. The respondents who disagreed alluded their security concern meanly on the vulnerability of the environment, which often, is not well secured to deter theft activities. The responses on the availability of PoS terminals indicated that more effort is still required as $30 \%$ of the respondents stated that the operators (or merchants) are still few compare to population of the city, while $55 \%$ agreed, and $15 \%$ were neutral. Reliability response indicated that majority of the respondents $(60 \%)$ agreed that PoS terminals are reliable for making electronic payment, while $28 \%$ disagreed. The respondents who disagreed maintained that sometimes transactions made through PoS are often delayed, or maybe worst, yet customers will be told to wait for hours or days for their transaction issues to be addressed. 


\section{Impact of PoS}
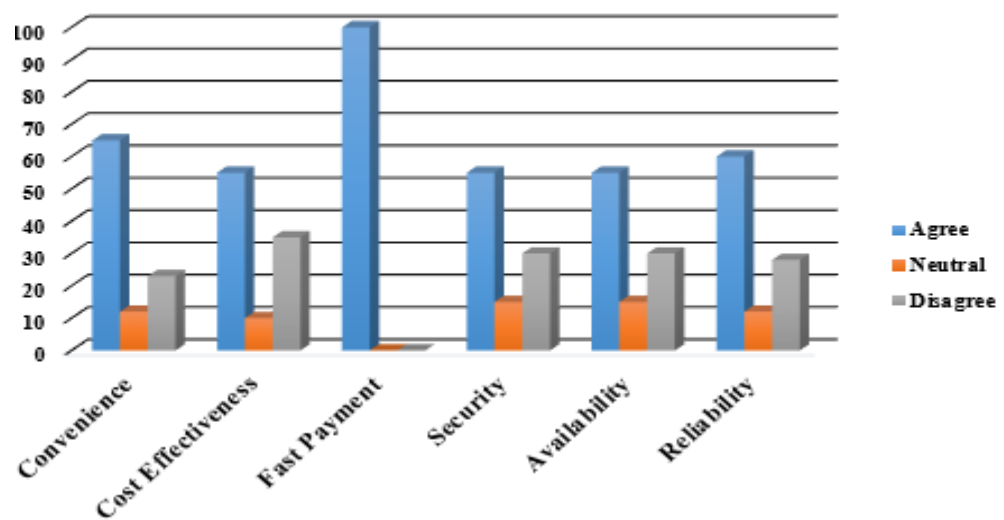

Fig. 3 Impact of PoS on respondents

\section{Level of Trust on PoS}

The level of trust the respondents have on the use of PoS for e-payment is shown in Fig. 4. The level of trust expressed by the respondents when asked are ranked as follow: very little (0-20), little (21-40), average (41-60), high (61-60), and very high (81-100). It can be seen that majority of the respondents indicated high level of trust $(55.5 \%)$. With $3.3 \%$ indicated little level of trust, $7.8 \%$ said they have little trust, while those that indicated average level or high level of trust are $16.7 \%$ respectively.

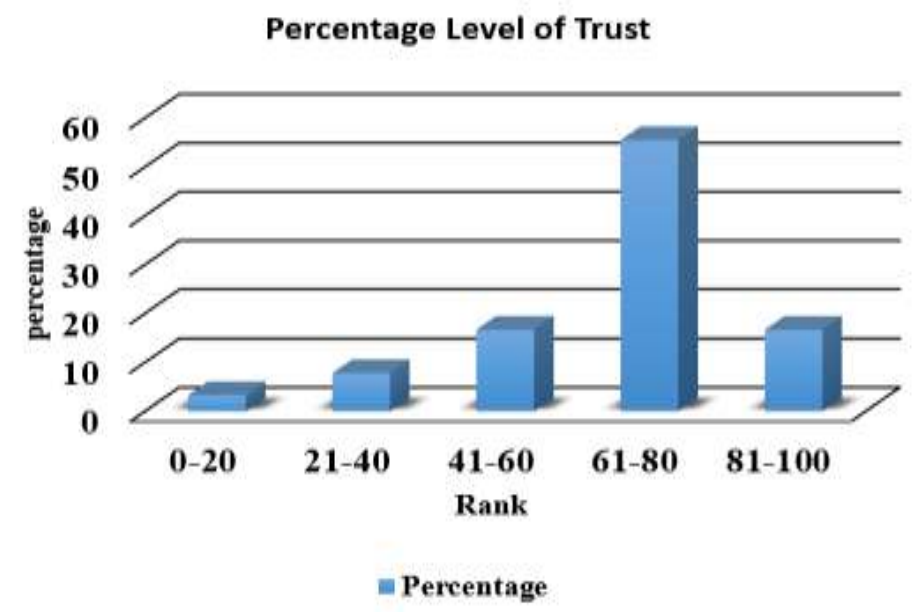

Fig. 4 Level of trust of respondents

\section{Challenges using PoS}

The responses from customers of different merchants visited based on challenges are presented in Fig. 5. The respondents were made to agree, disagree, or remain neutral (by saying "No answer") to the questions they were asked in terms of the challenges encounter using PoS for e-transaction. It shows the challenges to effective use of PoS. The figure shows the responses to efficient use of PoS in terms of availability of network, reliability of network, account debit without payment, security, and limited PoS points. Forty five per cent (45\%) of the respondents agreed that network is always available, $17 \%$ were neutral and $38 \%$ disagreed. On the reliability of network, $35 \%$ agreed, $17 \%$ neutral, and $48 \%$ disagreed. Majority of the respondents $(50 \%)$ representing half of the population of the respondents disagreed that they have been debited without being payed, $40 \%$ of the respondents agreed, with $10 \%$ maintaining neutrality. Majority of the respondents $(60 \%)$ agreed that PoS is a adequately secured for e-transaction, $10 \%$ were neutral, and $30 \%$ disagreed. Half $(50 \%)$ of the population of the customers interviewed disagreed that number of $\mathrm{PoS}$ is adequate, while $30 \%$ agreed, $20 \%$ were neutral. 


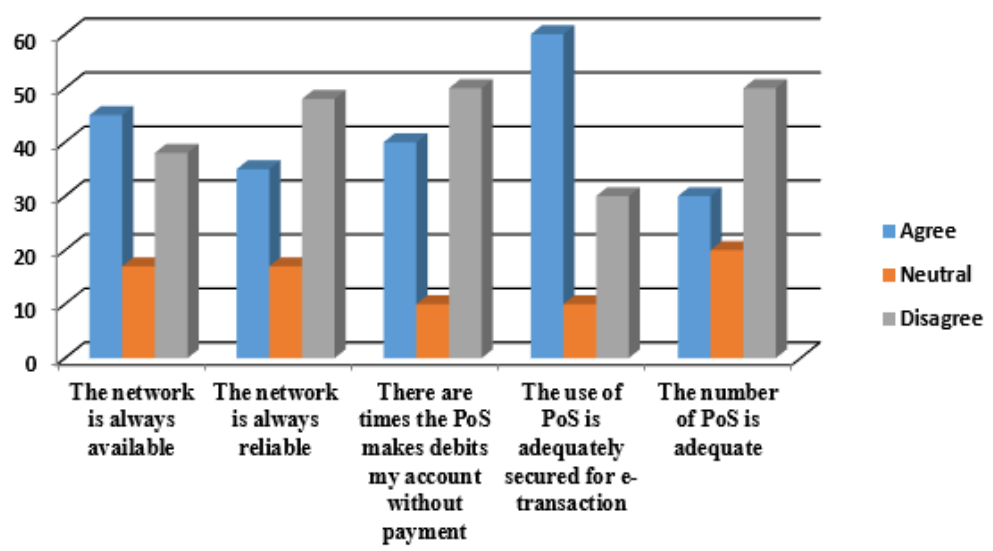

Fig. 5 Challenges to efficient use of Pos

\section{Conclusion}

This paper has studied the prospects and challenges of PoS as electronic payment system in Nigeria. It shows that significant number of customers interviewed expressed high level of trust on the use of PoS for carrying out their electronic transactions. Also, while majority of the respondents were of the opinion that it is convenient, all of them agreed that it is fast. However, significant number of respondents are still of the opinion that PoS transactions face some challenges to efficient electronic payment due to network failure, excessive charge incurred using it, limited number of PoS, and other financial transaction irregularities such as debiting customers even when transaction is incomplete.

\section{REFERENCES}

[1] C. K. Ayo and W. I. Ukpere, "Design of a secured unified e-payment system in Nigeria: A case study," African Journal of Business Management, vol. 4(9), pp 1753-1760, Aug. 4, 2010.

[2] N. Priscillia, "The Nigeria e-payment system,” Nigeria Monthly, 4(8): 25-27.

[3] P.N. Achebe, "The prospects and challenges of electronic finance in Nigeria," International Journal of Science and Management Studies, vol. 01(04), pp 60-64, Nov-Dec. 2018.

[4] Kingston, D-H, "PoS transaction in Nigeria hit N 1.4 trillion in 2017," BUSINESS INSIDER, 2018.

[5] I. Ogunfuwa, "Banks Registered 11, 506 New PoS Terminals in 1st Quarter, PUNCH News. Sourced on 14 Dec., 2018, 3.30pm.

[6] R. Nzaro and N. Magidi, "Assessing the Role of Electronic Payment Systems in Financial Institutions. A case of a Savings Bank in Zimbabwe," Global Journal of Management and Business Research: C Finance, vol. 14(2), 44-50, 2014.

[7] M. A. Kabir, S. Z. Saidin, and A. Ahmi, “Adoption of e-Payment Systems: A Review of Literature," Proceedings of the International Conference on E-Commerce (ICoEC 2015), 20-22 Oct. 2015, Sarawak, Malaysia.

[8] J. A. Tijani and A. O. Illugbemi, "Electronic Payment Channels in the Nigeria Banking Sector and its impacts on National Development," Asian Economic and Financial Review, vol. 5 (3), pp 521-531, 2015.

[9] O. O. Adeoti, "Challenges to the efficient use of point of (PoS) terminals in Nigeria," African Journal of Business Management, vol. 7(28), pp. 2801-2806, 28 July, 2013.

[10] T. C. Okeke, B. C. Nwatu,and G. A. Ezeh, "Predicting Consumer Adoption of Point of Sale (PoS) E-Payment System in Nigeria using extended Technology Acceptance Model,” British journal of Marketing studies, vol. 5(8), pp. 1-11, Oct. 2017.

[11] B. U. I Khan, R. F. Olanrewaju, A. M. Baba, A. A. Langoo, S. Assad, "A Compendious Study of online payment Systems: Past developments, Present Impact, and future Considerations," International Journal of Advanced Computer Science and Applications, vol. 8 (5), pp. 256-271 